\title{
Effect of Dust and High Temperature on Photovoltaics Performance in the New Capital Area
}

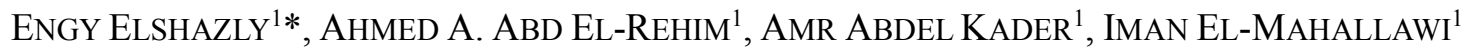 \\ ${ }^{I}$ Centre for Renewable Energy Faculty of Engineering \\ The British University in Egypt (BUE) \\ El-Sherouk 11837, Cairo, EGYPT
}

\begin{abstract}
The trend for integrating solar Photovoltaic Panels as an alternative renewable and sustainable energy source is growing in Egypt, North Africa and the Middle East. However, these efforts are not widely accepted by the society due to their lower efficiencies. The efficiency of the photovoltaic panels is affected by many environmental parameters, which have a negative impact on system efficiency and cost of energy, dust and increased panel temperatures being the most serious. This work presents the results of a case study conducted at The British University in Egypt at El-Sherouk city to study the effect of different parameters such as dust accumulation, water cooling and coating on their performance of both mono- and poly-crystalline panels at El-Sherouk City. The effects of high temperature and dust accumulation on different solar panels placed in natural outdoor conditions at El-Sherouk City were studied and the electrical performance of dusted, cleaned, and cooled PV panels is presented. The variation in the efficiency of mono-crystalline panels installed at different tilt angles, resulting from the accumulation of dust on their surface, was also studied. The results showed that the accumulation of dust on the surface of different types of solar panels can reduce the efficiency by $30 \%$. While the high temperature can reduce the efficiency by up to $10 \%$. The results showed that the power reduction percentage was $17 \%, 20 \%$,
\end{abstract}

$25 \%, 27 \%$ and $30 \%$ for tilt angles $60^{\circ}, 45^{\circ}, 30^{\circ}, 15^{\circ}$ and $0^{\circ}$; respectively. Tilt angles $15^{\circ}$ and $30^{\circ}$ showed to be optimal for the installation of the PV solar system, as they resulted the highest amount of output

power.

Keywords- Poly photovoltaics - Mono photovoltaics - Solar energy - Dust - High temperature.

Received: November 25, 2020. Revised: April 2, 2021. Accepted: April 12, 2021. Published: April 15, 2021.

\section{Introduction}

The integration of renewable energy in the national energy- mix for North African and Middle eastern countries is seriously considered and implemented. This action is also adopted by almost all nations to reduce dependance on fossil fuels, since they are identified as the major cause for increased greenhouse gases around the world [1]. Moreover, securing energy for rural and merging societies is a major requirement for sustainable growth and development in the region. In line with its 2030 development vision and after the significant reduction in solar energy cost during the last 10 years, the Government of Egypt has provided $37.2 \mathrm{~km}^{2}$ of land to NREA in Benban, in the town of Daraw Markaz of Upper Egypt, for the development of the Benban solar PV park [2]. The 41 solar power plants installed on the assigned area are foreseen to generate 1,800 megawatts, from the photovoltaic (PV) panels mounted on movable/ or fixed frames [3]. The implementation of the project will contribute to the achievement of $22 \%$ of Egypt's total 
power supply by 2022 and up to $40 \%$ by 2035 [4]. Similar efforts are reported in Middle Eastern and North African countries [5-6]. Figures 1 and 2 show the great development in solar PV capacity during the period from 2010 to 2019 . Where, Figure 1 shows the world's capacity from solar Photovoltaics while, Figure 2 shows the recent massive development in Egypt's Solar PV capacity especially during the last 5 years (in compliance with Egypt's vision 2030 released by the Ministry of Electricity and Renewable Energy in 2015) [7]. However, the main challenge threatening the success of these projects arises from the region's weather conditions such as high summer temperature, wind, dust, clouds, and shade, which has motivated researchers to investigate techniques for overcoming the present challenges, as well as taking advantage of the existing opportunities [8$18]$.

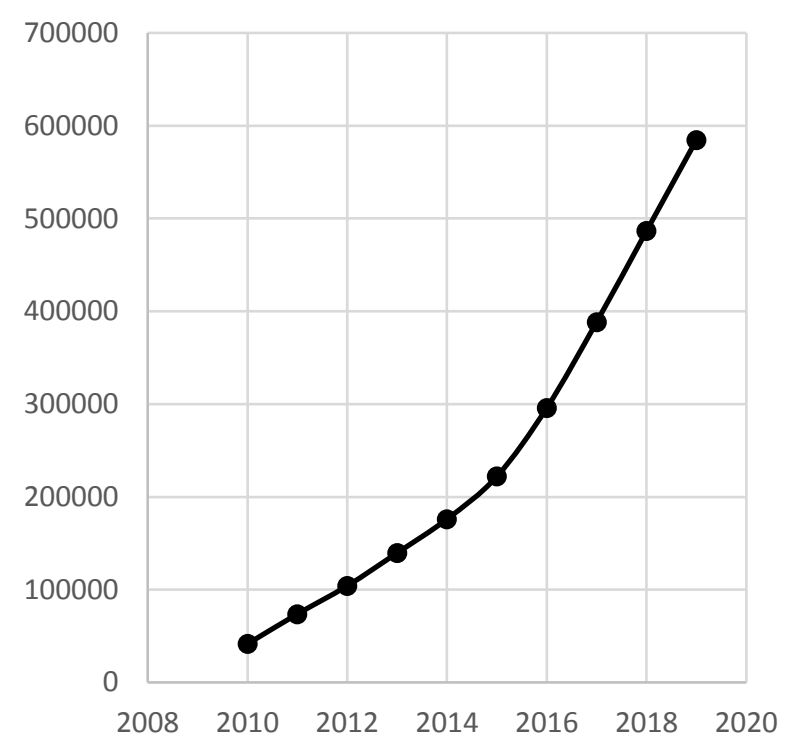

Figure 1: The World's Solar PV Capacity [5]

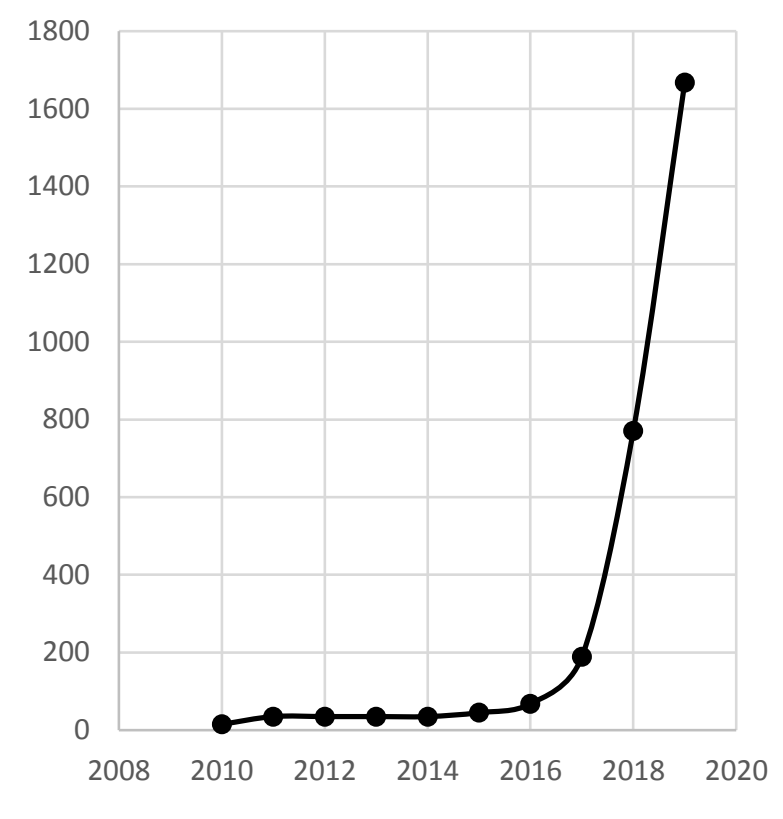

Figure 2: Egypt's Solar PV Capacity [5]

The accumulation of dust and pollutants on the cell's surface is a serious weather condition that negatively affects the performance of PV cells and reduces light transmissivity through the solar panels. The impact of Dust on PV efficiency is one of the most important problems facing PV utilization in dusty countries. The reduction in PV efficiency in desert areas ranges from $8.41 \%$ to $50 \%$ according to the reported results $[5,6,8$, 9]. Studies the impact of dust accumulation on PV panels in Egypt has indicated up to 17.4\%/month degradation in PV efficiency for the PV panels installed at $45^{\circ}$ angle to the south. The effect of the PV tilt angle on accumulated dust was studied experimentally using 100 glass samples. The results revealed that dust deposition decreases by up-to $70 \%$ for tilt angle 90 compared to tilt angle 0 for the same conditions [10]. On the other hand, the degradation in PV productivity due to dust accumulation was reported to reach $31-35 \%$ in Qatar, which is characterized by its high relative humidity and closeness to the desert [11]. The variation in the reported results from region to another is well understood due to the nature of dust. Dust is a 
natural phenomenon that occurs with the increase of windstorms, and the term refers to suspensions in air in the form of soil particles and particulate matter. These particulates result from a variety of natural and human activities and can remain suspended in air for a long time. The intensity of the dust increases as the sun's surface warms and wind speed increases. Dust follows the density of the type of land that passes through it, humidity, wind deviation, and air altitudes. These factors are changeable with different locations and, thus, dust accumulation effects differ from one place to another [5, 12, 13]. The aforementioned studies have shown that most of the photovoltaic installations in desert areas suffer from loss in efficiency due to the accumulation of dust, airborne dirt, sand particles from sandstorms, as well as high temperature in the summer season.

The significant loss in the energy harvesting efficiency of solar panels resulting from the adhesion of soiling requires regular cleaning in order to sustain a steady performance of PV panels, However, the traditional methods of manual cleaning are energy, labor, and timeconsuming processes. Another disadvantage of manual cleaning is the introduction of cracks and scratches on the PV surface. Researchers and engineers around the globe have been developing new cleaning methods, namely electrostatic, mechanical, and coating methods. Cost-wise, the electrostatic and mechanical methods are more expensive than most coating methods. The development of low-cost coatings is, therefore, an attractive goal for many researchers and in this context hydrophobic or hydrophilic coatings are used to the cover the glass surface. After applying those coatings, even if soiling occurs, the effort needed for cleaning is reduced, reducing cost significantly. However, the effect of sand erosion can cause the coating to deteriorate [14-15].
Efforts to mitigate the effect of increased summer temperatures on heating the panels ranged from applying direct cooling by a variety of methods to using nanofluids in the cooling application of PV/T systems [16-18].

In this context, the British University in Egypt (BUE), which is in a newly built area, works on solving the problems of its natural environment and community and has been working during the last year on evaluating and analyzing data showing the impact of dust and temperature rise on the performance of three different types of photovoltaic solar panels, mounted at BUE premises at El-Sherouk area.

El-Sherouk is a city located at the northeast of Cairo and at the north of New Cairo (Coordinates $30.1419^{\circ} \mathrm{N}, 31.6285^{\circ} \mathrm{E}$ ), in the province of Cairo, in Egypt, which is part of Greater Cairo. El-Sherouk is one of the cities of the third generation which was established by the decision of the Prime minister No. (326) of 1995. has been the establishment of the city within the framework of the efforts of the Egyptian state for urban expansion to achieve several development goals, the most important goal is to absorb the expanding population and to ease population pressure on the aging capital, and the redistribution of the population within the Greater Cairo area, and at the same time raise the standard of living of the population of the region, through the provision of new job opportunities from industrial projects, which will be set up in the city.

El-Sherouk essentially has a hot desert climate, generally extremely dry all over the capital in addition to rarity of rain, extreme heat during summer months is also a general climate feature of El-Sherouk although daytime temperatures are more milder during autumn and winter. 


\section{Experimental Setup}

The experimental work covers two main stages which are:

Stage one, which depends on selecting six solar panels and trying to test different installation and operating conditions such as:

- The effect of dust accumulation and cooling by water on Mono and Poly-crystalline panels at fixed tilt angle of $30^{\circ}$ and directed to the South direction. The experiment is held on two different types of solar panels: monocrystalline with $280 \mathrm{Wp}$ and polycrystalline with $270 \mathrm{Wp}$. The tested panels are of dimensions $1.6 \mathrm{~m}$ height, $1 \mathrm{~m}$ width and $1.6 \mathrm{~m}^{2}$ total area, figure (3). The system is installed in a natural outdoor area in El-Sherouk City, Cairo which is located northeast of Cairo and is known for its desert hot climate condition (30.144212 latitude and 31.639718 longitude).

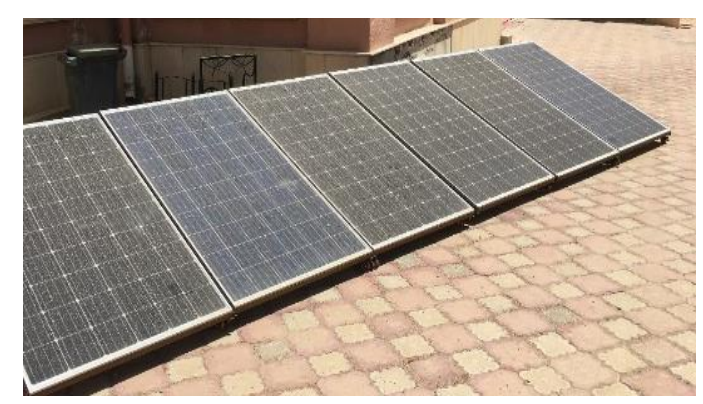

Figure 3: Tested solar panels held on $30^{\circ}$ tilted holders facing South direction.

The experimental measurements are performed for three successive days in July, each with different conditions as shown in Table 2:

\section{Table 2: Test conditions:}

\begin{tabular}{|l|l|}
\hline $\begin{array}{l}\text { Day } \\
\text { (average Irradiation } \\
\left.950 \mathrm{~W} / \mathrm{m}^{2}\right)\end{array}$ & Tested conditions \\
\hline Day 1 & $\begin{array}{l}\text { Panels with accumulated } \\
\text { dust for one month }\end{array}$ \\
\hline Day 2 & Cleaned panels \\
\hline Day 3 & Cleaned and cooled panels \\
\hline
\end{tabular}

The impact of tilt angles varying from 0 to 60 degrees (achieved by manually adjusting the facing angle) on dust accumulation and efficiency degradation in dusted panels. The measurements are taken for a whole month (May). As compared to flat installations, the tilt angle of an array will increase solar PV energy production by up to $20 \%$. adding 15 degrees to a site's latitude in the winter and subtracting 15 degrees from a site's latitude in the summer will improve energy production.

- After applying a simple formula coating layer by adding nanoparticles to phase change material on the panels, the results were reported for seven consecutive days with an average radiation of $950 \mathrm{~W} / \mathrm{m}^{2}$.

A PV solar analyzer, model PROVA 1011, is used to measure solar radiation, the temperature of solar panels through wireless sensors, and then develops the I-V characterization curve. The measured parameters are the short circuit current, the maximum current, the open voltage, the output power, and the weather parameters, solar radiation, and the panel's surface temperature.

Stage two, which depends on recording the output of a $100 \mathrm{~kW}$ PV on grid power plant which is in a desert area in the east of Cairo (Cairo Suez direction). This region is affected by many severe sandstorms, especially during the months of March, April and May of each year. The area temperature is ranging from $20^{\circ} \mathrm{C}$ in winter and $45^{\circ} \mathrm{C}$ in summer. 
This grid connected PV power plant has a yearly energy yield of $200,000 \mathrm{KWh}$. The plant consists of $250 \mathrm{PV}$ modules with a rated power of 400 Watt and total surface area of $2.6 \mathrm{~m}^{2}$ each. This results in an overall area of $650 \mathrm{~m}^{2}$.

\section{Results and Discussion}

\subsection{Stage one; results of the individual tested panels}

In this stage, all experiments were carried out at the British University in Egypt, El-Sherouk City, Cairo. Figure 4 shows the average monthly solar radiation on the tested location in $\mathrm{kWh} / \mathrm{m}^{2} /$ day. The data was collected using a BUE weather station (WS-GP1) and logged every five minutes. The monthly incident solar radiation at $30^{\circ}$ module inclination angle is shown in the diagram. The figure depicts high solar irradiance, especially during the summer months, for the defined region.

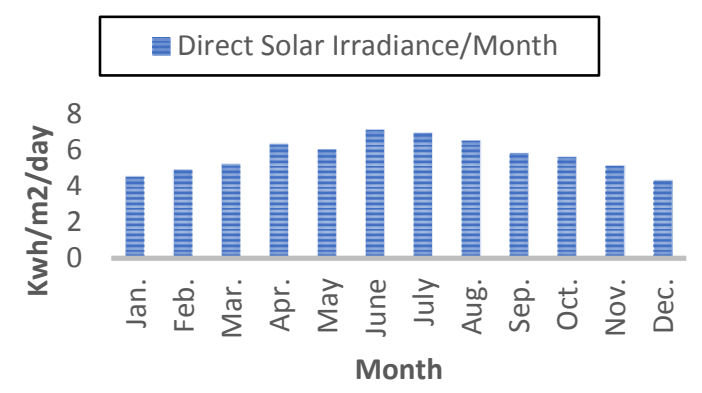

Figure 4: the average solar energy $\mathrm{kWh} / \mathrm{m}^{2} /$ day over the months of the year in Egypt

\subsubsection{Effect of tilt angle on dust accumulation}

The tilt of the PV panel is measured in degrees from horizontal. A 0-degree tilt is found on a flat roof, while a 90-degree tilt is found on a vertical wall mount. The performance of a solar PV system can be improved by optimizing the tilt angle, whether installing the solar panels on a flat roof or a pitched roof.
If the PV panel always faces the sun directly, the performance is the greatest. Since the sun's position varies during the day, it's difficult to face the sun directly unless a system uses a 2-axis solar tracker. However, by tilting the array at an optimum angle, the performance can be maximized.

A test was performed to figure out the optimal tilt angle of the PV modules to be installed in the specified location. Figure 4 shows that the efficiency of angles $15^{\circ}$ and $30^{\circ}$ are the highest compared to the output power of the other angles. Therefore, the optimal tilt angles to be used in the installation of the solar panels are preferred to be in the range of $15^{\circ}$ to $30^{\circ}$, followed by angle $45^{\circ}$.

The results of angle $0^{\circ}$ are approximately near to the results of angle $45^{\circ}$. Therefore, it can be also used in specific conditions if there are no options in choosing the installation angle. Angel $60^{\circ}$ has the lowest power output because of the high tilt angle and the lower radiation reaching the solar panel. Therefore, angle $60^{\circ}$ is not preferred to be used as shown in Figure 5.

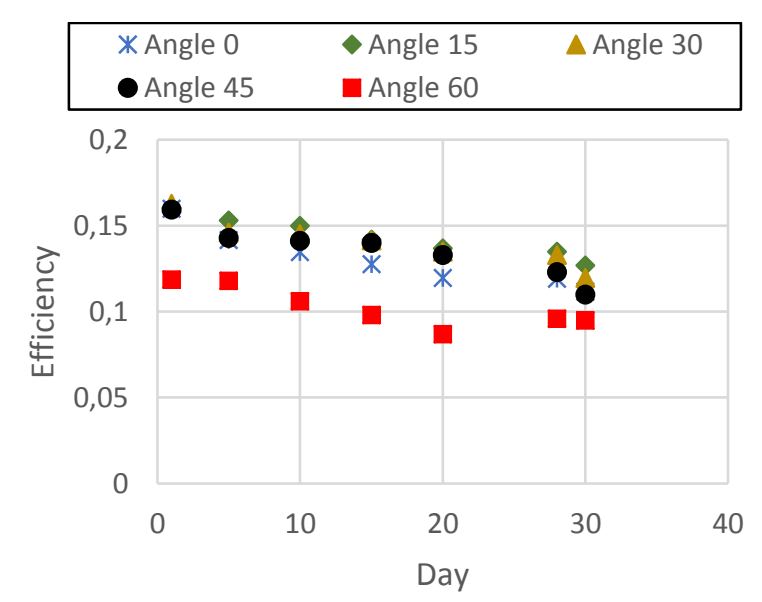

Figure 5: The output power for different tilt angles for Mono/290 Wp 
The results presented in Figure 5 show that the panels with tilt angle $30^{\circ}$ produce higher power than those with tilt angle $15^{\circ}$, at the start of the experiments, which indicates that the solar panels with a $30^{\circ}$ tilt angle produce the highest power in clean conditions. Though the tilt angle of $30^{\circ}$ remains the highest in power output, the difference between the inclination angles tends to decrease towards the end of the one-month experiment upon becoming dusty. The Figure shows that the difference between the output power values decreases till it reaches a minimal after 30 days with dust accumulation on the solar panels. The maximum value for difference occurs in the first week in favor of the clean panels. It can be concluded from the curve that the output power is highly influenced by the tilt angle for the clean panels, while the effect of the tilt angle tends to decrease for the dusted conditions for both inclination angles of $15^{\circ}$ and $30^{\circ}$.

\subsubsection{Effect of environmental conditions}

Figures 6 and 7 show the performance of mono and poly-crystalline solar panels with the accumulation of dust and the cooling effect. First is the irradiance effect, which can be seen in the 2 graphs, as the efficiency of the panels increase from 09:00 Am reaching its maximum at 12:30 PM, which is approximately the time at which there is maximum irradiance. Efficiencies of the panels then start to decrease till the end of the testing interval as the irradiance also starts decreasing with time. Second, is the dust effect which is shown by the efficiency increase by 20 $\sim 30 \%$ after it was cleaned on the second day of testing.

Third, is the effect of water cooling, where the panels were cooled every 2 hours. The curves for all types show higher efficiency by approximately $7 \%$ than the cleaned panels. The temperature of the panels at noon is usually around $58^{\circ} \mathrm{C}$ on a normal day without cooling compared to an average of $44^{\circ} \mathrm{C}$ obtained directly after cooling. The solar panels' efficiency was calculated by the following equation:

$\eta=\frac{\mathrm{v}_{\mathrm{OC}} * \mathrm{I}_{\mathrm{SC}} * \mathrm{FF}}{P_{\text {in }}}$

Where $V_{o c}$ is the open-circuit voltage; $I_{s c}$ is the short-circuit current; FF is the fill factor and $\eta$ is the efficiency.

As shown in the Figures, the most important factor that affected the solar panels' performance was the dust accumulation on the surfaces. Thus, another test was performed to study the performance degradation due to dust accumulation by placing initially cleaned panels in the same place and keeping them without removing dust for four weeks.

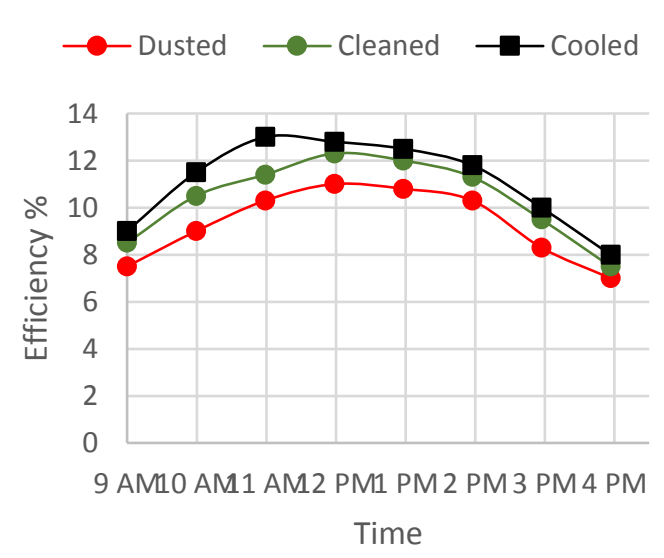

Figure 6: Monocrystalline-280Wp solar panel's efficiency measurements for three different conditions 


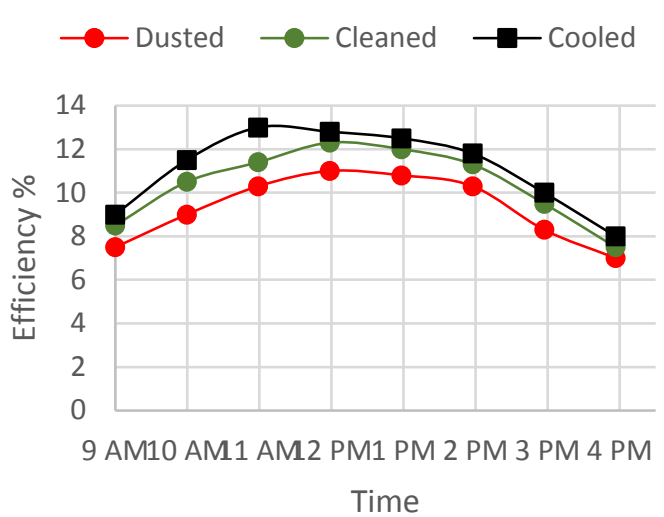

Figure 7: Polycrystalline-270 Wp solar panel's efficiency measurements for three different conditions

The peak hour can be defined as around solar noon, when the PV module produces its maximum energy, and the off-peak hours can be defined as any time after that (sunrise and sunset).

Figure 8 shows the electrical efficiency degradation during the examined period under approximately the same temperature and solar radiation conditions for the two different solar panels. The Figure shows that linear degradation starts at a maximum value of $10 \%$ with clean conditions and the degradation keeps increasing up to the four testing weeks without cleaning, which reflects the big influence of dust accumulation on the solar panels.

The findings show that keeping solar photovoltaics clean and cool will increase their efficiency by about $20 \%$, demonstrating the significance of these two factors making it an issue of great concern.

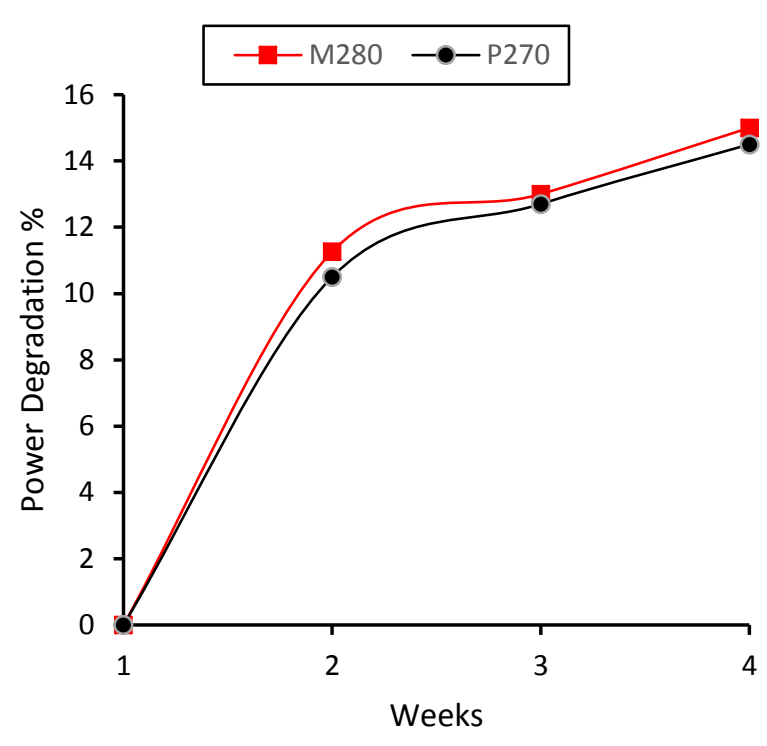

Figure 8: The electrical efficiency degradation during the examined period for poly- and monocrystalline $\mathrm{Si}$ modules

Finally, the effect of heat on solar PV efficiency is illustrated in Figure 9, where the temperature was measured for $\mathrm{M} / 280$ and $\mathrm{P} / 270$ solar panels at the same solar radiation $\left(900 \mathrm{~W} / \mathrm{m}^{2}\right)$ for different panels' temperatures. The curves show that the increase in temperature by $10^{\circ}$ results in a degradation of approximately $7 \%$ in the panel's efficiency. Also, the efficiency may increase as the temperature goes up. This is possible when there is a lot of solar radiation and a lot of wind. The wind convection around the solar modules keeps the temperature from rising. 


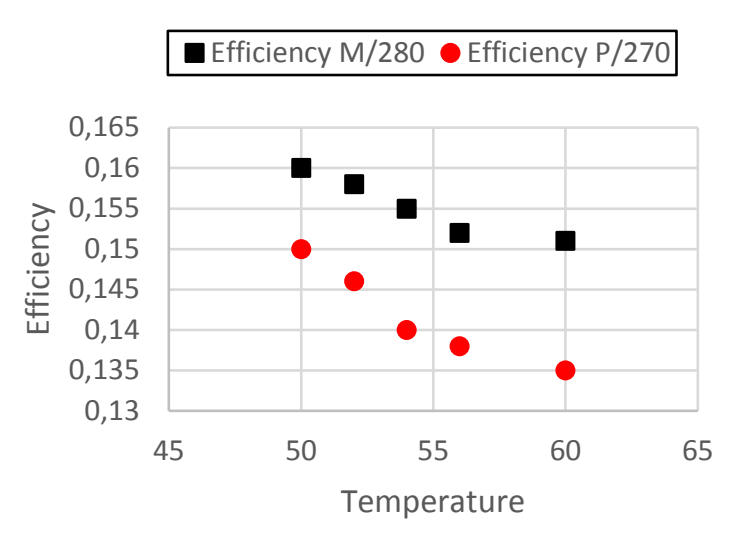

Figure 9: Effect of Temperature on PV efficiency

\subsubsection{Nano Coating}

Cleaning solar panels is one of the most important and economically urgent problems for the Mediterranean countries. Currently, most solar panel installations rely on one or a combination of these cleaning methods; natural methods (rain and wind), mechanical methods (manual cleaning, or scrubbing), and passive self-cleaning technologies. The cleaning methods are natural means, mechanical means, self-cleaning nano-film, and electrostatic means [16].

The amount of sunlight that reaches the solar cells in a solar panel decreases due to factors such as soil and organic dirt. Even if the photovoltaic panel's surface is clean, sunlight is refracted and mirrored due to the reflective effect of the cover glass surface. The solar rays that remain are broken and enter the solar cell. When the amount of sunlight decreases, so does the amount of electricity generated. To address these issues, anti-reflective and self-cleaning coatings are applied to photovoltaic solar cells on the cover glass.

Paraffin Wax and Glycerin are phase change thermoplastic materials used for energy storage techniques. However, their applications are limited because of their low thermal conductivity [19]. Since anti-reflection coatings are commonly made of $\mathrm{SiO}_{2}, \mathrm{TiO}_{2}, \mathrm{ZrO}_{2}$, while $\mathrm{Al}_{2} \mathrm{O}_{3}$ and $\mathrm{TiO}_{2}$ for self-cleaning applications [20], a simple formula for self-cleaning coating was investigated at the Center of Renewable Energy Lab (CRE). The prepared material was made-up of Glycerin and $\mathrm{Al}_{2} \mathrm{O}_{3}$ nanoparticles. The nanoparticle concentration was $5 \mathrm{wt} \%$ of the base carrier and was prepared by applying magnetic stirring for one hour. The design of the coating material was based on nano-materials properties that have been observed in other applications (e.g., enhanced absorbance of nanoparticles observed in selective solar applications, or good heat storage capacity observed in polymeric-based materials used for phase change materials. Figure 10 shows the $\mathrm{P} / 270$ solar panels; one without coating and the other after applying the prepared nano-coating, for comparison at the same weather conditions.

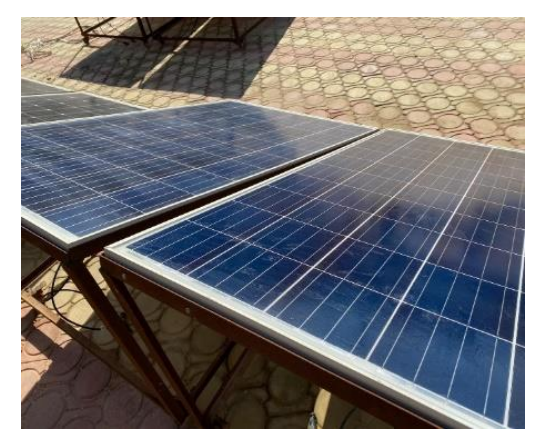

Figure 10: Solar Panel after applying the prepared Nanocoating.

The results which were obtained after applying the prepared coating for one week and repeating the measurements at noon each day are shown in Figures 11 and 12. The reported results show an improvement in the solar panel's obtained output power by about $1 \%$. The results at the beginning of the experiments showed a decrease in the panel's temperature of approximately $5^{\circ} \mathrm{C}$ and a 
$1 \%$ increase in electrical efficiency. The decrease in the temperature is owed to the higher heat storage properties of the polymeric materials. Figure 12 (showing the change in electrical efficiency through the seven testing days) confirms that the electrical efficiency of the coated panels increased during all the examined periods above the uncoated panels.

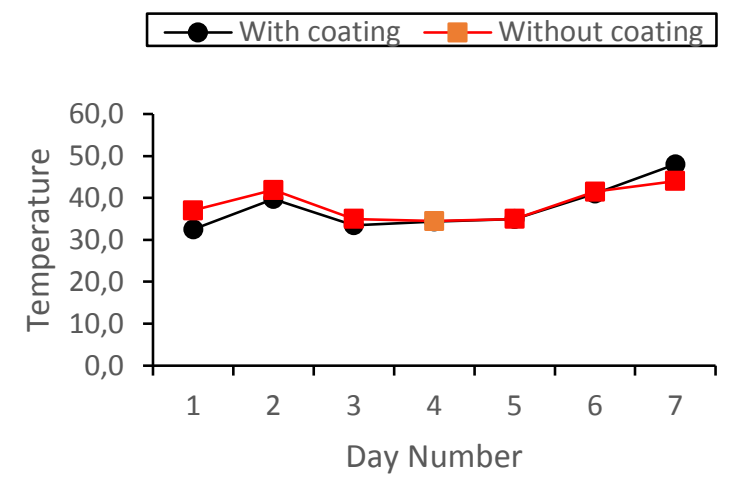

Figure 11: The temperature improvement for Mono/290 $\mathrm{Wp}$

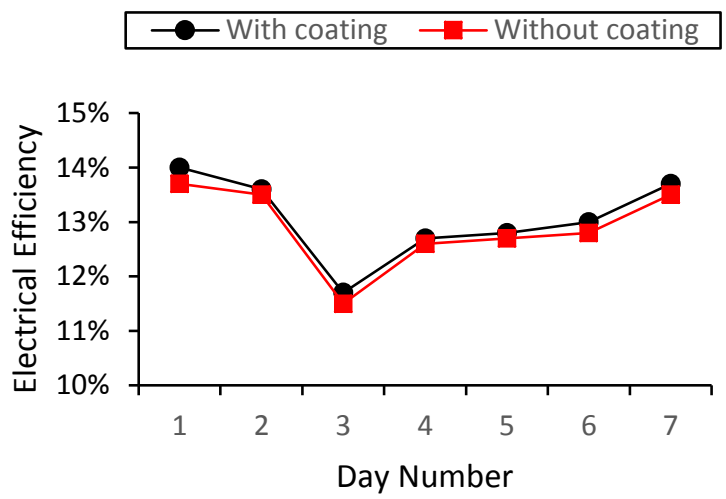

Figure 12: The output power improvement for Mono/290 $\mathrm{Wp}$

The problems related with coatings are usually scratching the glass cover by additional wiping, and the better the self-cleaning performance (better super-hydrophobicity), the worse the environmental stability. Better hydrophobicity means a higher aspect ratio of nanostructures, which are more prone to damage by mechanical impact. Also, photocatalytic coatings contain nanoparticles, which could be released into the environment. However, even with using coatings, efforts for automatic sensing and cleaning of solar panels are needed and could be realized using technology, which would sense contamination and start cleaning immediately, without human intervention. These active selfcleaning technologies would rely on electrostatic and ultrasonic methods and management of the transition of the ultrasonic cleaning process from a bath environment directly to the solar panel [21].

\subsection{Stage two; results of the grid connected PV plant.}

The daily energy loss along 50 weeks testing period caused by dust deposited on the surface of the PV modules is recorded to be $32 \%$ as shown in figure 13. The results revealed that the majority of the loss, about $20 \%$, resulted in the first eight weeks, while $8 \%$ of the loss resulted over the next 12 weeks and the rest, $4 \%$, resulted over last 30 weeks. Based on this analysis, implementing a cleaning methodology every 6-8 weeks will be beneficial for the operation of the PV modules which are corresponding to about $15-20 \%$ loss in the electrical power produced.

Figure 14 shows a comparison of the output AC electrical power for the PV power plant with dust accumulation (6 weeks dust accumulation) and with a cleaned one from sun rise to sun set on a selected day. 


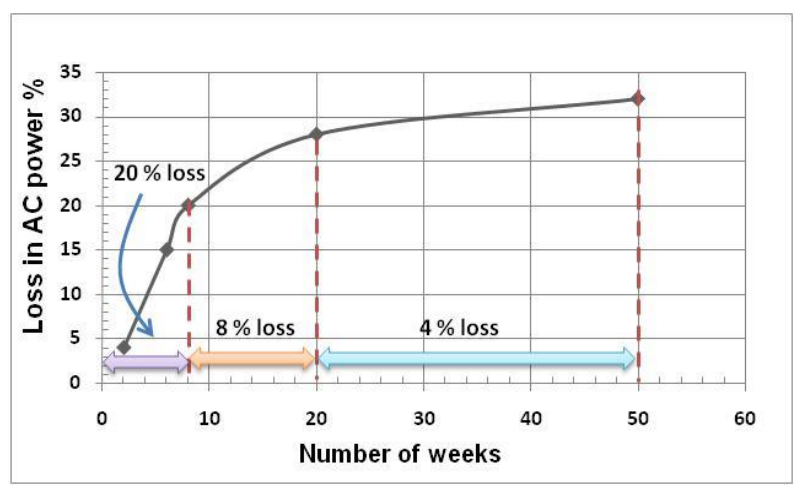

Figure (13) Loss in AC power due to dust accumulation over the tested period of 50 weeks.

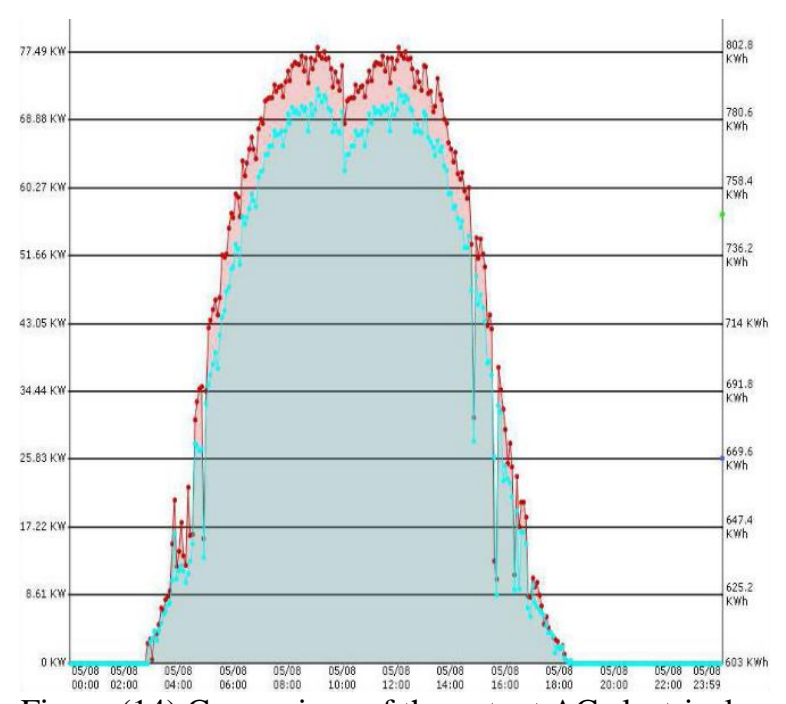

Figure (14) Comparison of the output AC electrical power for the PV power plant with dust accumulation (6 weeks dust accumulation) and a cleaned one.

\section{Conclusions}

The influence of some weather conditions such as dust and high temperature on the performance of two different solar PV module technologies was studied. Based on the findings of the inquiry, the following conclusions may be drawn:

1- The impact of irradiance, high temperature, and dust deposition on two different solar panels has been investigated in this paper. High temperature can cause a 5\% reduction in efficiency, while dust accumulation can cause a $20 \%$ reduction in efficiency in all types studied.

2- The loss of electrical efficiency has been also studied, and it is discovered that in Egypt's weather conditions, solar panels would lose half of their full efficiency after just one month without cleaning.

3- For Egypt's conditions, the best tilt angle is $30^{\circ}$. For dusted settings, the tilt angle's impact appears to diminish.

4- The use of new formula self-cleaning coatings has resulted in a $1 \%$ improvement in panels' efficiency.

5- Different nanomaterials with different thermal properties and concentrations need to be studied in the future to decide how to boost panel performance while reducing cleaning requirements.

6- The results revealed that the electrical power loss over 50 weeks of examination for an actual PV plant is $32 \%$, where $28 \%$ was recorded in the first 20 weeks and only $5 \%$ was recorded in the next 30 weeks.

\section{Acknowledgment}

The authors would like to express their deepest appreciation to the Centre of Renewable Energy in the British University in Egypt for their technical assistance and support in this project.

\section{References:}

[1] Al- Maamary, M.S.Hilal, H.A. Kasem, M.T. Chaichan, "The impact of oil price fluctuations on common renewable energies in GCC countries", Renewable and Sustainable Energy Rev. 75, pp. 989-1007, 2017. 
[2] Z.A. Darwish, H.A. Kasem, K. Sophian, M.A. Alghoul, M.T. Chaischan "Impact of some environmental variables with dust on solar photovoltaic performance: review and research status", Research gate, pp. 152-159, 2013.

[3] https://www.nsenergybusiness.com/projects/ benban-solar-park/

[4] NREA, 2019 Annual Report.

[5] Muhammed J. Adinoyi, Syed A.M. Said, "Effect of dust accumulation on the power outputs of solar photovoltaic modules", Renewable Energy, Volume 60, 2013, Pages 633-636.

[6] Yusuf N. Chanchangi, Aritra Ghosh, Senthilarasu Sundaram, Tapas K. Mallick, "Dust and PV Performance in Nigeria: A review, Renewable and Sustainable Energy Reviews, Volume 121, 2020, 109704.

[7] IRENA, Renewable Energy Statistics, 2020.

[8] M. Dida et al., "Output power loss of crystalline silicon photovoltaic modules due to dust accumulation in Saharan environment", Renewable and Sustainable Energy, Rev. 124, pp. 109-787, 2020.

[9] L. Dorobantu et al., "The effect of surface impurities on photovoltaic panels, " Renewable Energy Power Quality, pp. 622626, 2017.

[10] H.K. Elminir et al., "Effect of dust on the transparent cover of solar collectors Energy Conversion and Management, pp. 31923203, 2006.

[11] S. Essalaimeh et al., "Electrical production for domestic and industrial applications using hybrid PV-wind system", Energy Conversion and Management, pp. 736-743, 2013.

[12] B. Guo et al., "Effect of dust and weather conditions on photovoltaic performance in Doha, Qatar", 2015 First Workshop on Smart Grid and Renewable Energy (SGRE), pp. 16, 2015.

[13] Emad A. Sweelem, E. T. El Shenawy, Abd El-shafy A. Nafeh; "Effect of Different Dust Accumulation on the Performance of PV Module in Egypt", International Journal of Advanced Information Science and
Technology (IJAIST)” Vol.44, No.44, December 2015

[14] Gaofa He, Chuande Zhou, Zelun Li; Review of Self-Cleaning Method for Solar Cell Array, Procedia Engineering 16 (2011) 640 645.

[15] n- Tech Research, "Self-cleaning Technologies for Solar Panels", n-Tech Research Publication, May 2018; https://www.ntechresearch.com/wpcontent/uploads/2018/05/with-cover-selfcleaning-solar-panels-article-0530.pdf

[16] M.T. Chaichan, H.A. Kazem, "Experimental analysis of solar intensity on photovoltaic in hot and humid weather conditions", International Journal of Science Engineering, pp. 91.96, 2016. [8]

[17] A. Ibrahim et al., "Comparison study of indoor/outdoor experiments of a photovoltaic thermal $\mathrm{PV} / \mathrm{T}$ system containing $\mathrm{SiC}$ nanofluid as a coolant", Energy, pp. 33-44, 2018.

[18] A. Bayoumi, M. A. Nosier, O. E. Abdelatiff, N. A. Mahmoud and A. S. G. Khalil, "Modeling and simulation of a photovoltaic/thermal hybrid system using different back-pipe structures," 2016 11th International Conference on Computer Engineering \& Systems (ICCES), Cairo, Egypt, 2016, pp. 489-494, doi: 10.1109/ICCES.2016.7822054.

[19] Maitham Jameel Zaidan,Mohammed H. Alhamdo, "Improvement in Heat Transfer Inside a phase change Energy System", International Journal of Mechanical \& Mechatronics Engineering, Vol. 18, No. 5, pp.33-46, 2018.

[20] Ali Samet Sarkin, Nazmi Ekren, Safak Saglam, "A review of anti-reflection and selfcleaning coatings on Photovoltaic Panels", Solar Energy Journal, Vol. 199, pp. 63-73, 2020.

[21] Boris Kobrin, "Self-cleaning Technologies for Solar Panels", n-Tech Research Publication, 2018.

Creative Commons Attribution License 4.0 (Attribution 4.0 International, CC BY 4.0)

This article is published under the terms of the Creative Commons Attribution License 4.0

https://creativecommons.org/licenses/by/4.0/deed.en_US 